\title{
Dehydration and Hemodynamic Changes as Causa Mortis Associated with Trichuris vulpis in a Dog
}

\author{
Eric Arantes da Silva ${ }^{1}$, Igor Borges Oliveira ${ }^{1}$, Thâmara Rossi Martins da Silva ${ }^{1}$, \\ Andreia Vitor Couto do Amaral'2, Raphaella Barbosa Meirelles-Bartoli' ${ }^{2}$, Ísis Assis Braga ${ }^{2,3}$, \\ Klaus Casaro Saturnino² \& Dirceu Guilherme de Souza Ramos ${ }^{2}$
}

\begin{abstract}
Background: Trichuris vulpis, a species that belongs to Trichuris and shows a cosmopolitan distribution, parasitizes the gastrointestinal system of dogs causing trichuriasis. The infection occurs owing to ingestion of larval eggs and subsequent fixation of their adult form in the large intestine of the host. The objective of this paper is to report the case of a Border Collie dog that arrived at the Veterinary Pathology and Parasitology Laboratory (LPPV) of the Federal University of Jataí (UFJ) after exhibiting signs of intense dehydration and sudden death caused by severe $T$. vulpis infection, and to elucidate the macroscopic and microscopic histopathological correlations observed during necropsy.

Case: A 7-year-old male Border Collie dog was referred for routine necroscopic examination on suspicion of death from intoxication. In the history, there were reports of bone ingestion, restlessness, and polydipsia for three days, followed by sudden death. Although the animal presented an adequate body state during the necroscopic procedure, enophthalmia and pale oral and ocular mucosa were observed, which are characteristic signs of severe dehydration and anemia. On opening the abdominal cavity, the visceral serosa were found to be stained and severely dry. Greenish mucous content was observed throughout the intestine, and in the large intestine, a moderate amount of mucus associated with high parasitic infestation by elongated parasites attached to the mucosa was identified. The parasites were harvested, stored in airtight vials containing $70 \%$ alcohol, processed, and subsequently identified as T. vulpis.

Discussion: The necroscopic findings associated with the histopathology were compatible with T. vulpis infestation at high parasite intensity, with severe destruction of the intestinal mucosa and inability of water absorption, resulting in severe dehydration. In cases of parasitism, villous atrophy with crypt hypertrophy occurs, a fact observed in the present case. Possibly crypt hypertrophy occurs prior to villous atrophy, and occurs independently of previous lesions of the absorptive compartment. This results in poor absorption. Advanced loss of gastrointestinal tract fluids can usually be extensive and lead to progressive dehydration with loss of isotonic and hypertonic fluids, which can also be observed in the observation of blood components, severely accelerating changes such as hypovolemia and posterior hemoconcentration. Hypovolemia from severe dehydration also decreases renal perfusion and reduces the rate of glomerular filtration. Hypovolemia also leads to decreased blood pumping capacity, which may lead to heart failure and pulmonary circulatory disorders with notable effects on gas exchange, which may cause hypoxemia and possibly lethal metabolic acidosis. The necropsy performed on the animal found a severe dehydration that could be sustained mainly owing to signs of hypovolemia, associated with a series of pathophysiological events with the massive presence of parasites identified as Trichuris vulpis. The damage caused to the intestinal mucosa by the oral stylet, the movement, and toxins of the parasites led to a severe condition of villosities destruction and tissue necrosis, leading to a large loss of the absorption function of nutrients in the intestines and especially of water, resulting in a condition of severe dehydration. This imbalance of system functioning also alters cardiac function because of increased blood viscosity generating possible lardaceous clots, which in turn are indicative of anemia. This cycle of deleterious changes can result in hypovolemic shock and consequent sudden death.
\end{abstract}

Keywords: anemia, necropsy, parasitism, trichuriasis. 


\section{INTRODUCTION}

Owing to the tropical climate with favorable temperature and humidity, the Brazilian territory is an ideal environment for egg deposition and preservation, in addition to the evolution of the larvae of several canine gastrointestinal parasites [17].

Several studies have shown that the most prevalent canine intestinal parasites are the nematodes Ancylostoma spp., Toxocara spp., and Trichuris vulpis $[11,12,16,17]$. Among the group of nematodes, the parasites of Trichuris are some of the most commonly found, occurring in various geographical regions and with climatic differences. This genus has around 80 species and can parasitize several animals in addition to humans [20].

Trichuris vulpis is the main species of this genus that parasitizes the gastrointestinal system of dogs, and its infection occurs through the ingestion of eggs containing the primary form of their larvae (L1), that after hatching, attach themselves to the mucosa of the caecum and large intestine, feeding on the mucous epithelium, tissue fluids, and blood $[8,17]$.

Trichuriasis, a disease caused by T. vulpis, has symptoms such as anemia, dehydration, weight loss, and anorexia [19]. Depending on the parasitic load present in the host, the disease progression may evolve to the death of the animal [4].

The objective of this paper is to report the case of a Border Collie dog that arrived at the Veterinary Pathology and Parasitology Laboratory (LPPV) of the Federal University of Jataí (UFJ) after exhibiting signs of intense dehydration and sudden death caused by severe T. vulpis infection, and to elucidate the macroscopic and microscopic histopathological correlations observed during the necropsy.

\section{CASE}

In September 2017, a seven-year-old male Border Collie dog was referred to the Veterinary Pathology and Parasitology Laboratory of the Federal University of Jataí (LPPV/UFJ), for routine necroscopic examination on suspicion of death from intoxication. In the history, there were reports of bone ingestion, restlessness, and polydipsia for three days, followed by sudden death.

Although the animal presented an adequate body state during the necroscopic procedure, enophthalmia and pale oral and ocular mucosa were observed, which are characteristic signs of severe dehydration and anemia. On opening of the abdominal cavity, the visceral serosa were found to be stained and severely dry. Reinforcing the presence of severe dehydration, the tracheal and bronchial mucosae were also diffusely dry and hypocolored. Lardaceous clots were observed in small quantities in the cardiac ventricles of the heart. The gallbladder was distended, with a moderate amount of thickened gallbladder mud. Greenish mucous content was observed throughout the intestine, and a moderate amount of mucus associated with high parasitic infestation by elongated parasites attached to the mucosa was identified in the large intestine.

The parasites were harvested, stored in airtight vials containing 70\% alcohol, and processed according to the method described by Hoffman [9], and subsequently identified as T. vulpis, according to the taxonomic keys defined by Anderson et al. [2], specific to helminths.

Tissue samples from the lung, heart, central nervous system, spleen, kidney, intestine, pancreas, and liver were collected for histopathological examination. Samples (five-microns in thickness) were fixed in $10 \%$ buffered formaldehyde for $48 \mathrm{~h}$ and routinely processed in hematoxylin ${ }^{1}$ and $\operatorname{eosin}^{2}$ for further analysis in bright field microscopy (Nikkon Eclipse E2003).

Microscopically, in the pancreas, spinal cord, heart, kidneys, and liver, thrombi were observed in blood vessels of various calibers, including some in the process of recanalization. In the kidneys, multifocal glomerular tufts were retracted, with increased Bowman spaces. Many proximal contoured tubules had lining cells with granular and fragmented cytoplasm, with some free cells in the tubular lumen, characterizing necrosis and tubular obstruction.

In the liver, hepatocytes presented cytoplasm ranging from granular to vesicular, mainly from the centrilobular zone, characterizing moderate hydropic degeneration. The spleen had a large hyperplastic area, especially in the white pulp part. The lungs had diffuse congestion of the blood capillaries, associated with multifocal areas of atelectasis and thickening of the alveolar septa (Figure 1). The intestinal mucosa was diffusely necrotic (Figure 2).

\section{DISCUSSION}

The necroscopic findings associated with the histopathology were compatible with $T$. vulpis 


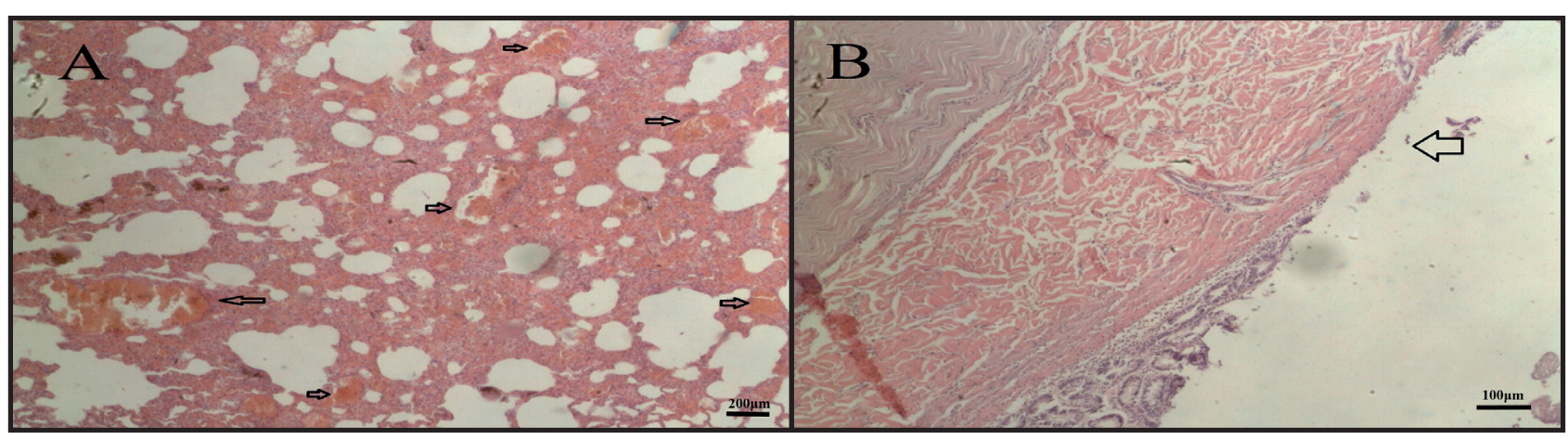

Figure 1. A- Lung with multiple areas of atelectasis and thickening of the alveolar septa associated with diffuse capillary congestion (arrows). B- Small bowel mucosa showing (arrow) the destruction of the epithelium caused by Trichuris vulpis.

infestation at high parasite intensity, with severe destruction of the intestinal mucosa and inability of water absorption, resulting in severe dehydration.

The intestinal mucosa is lined with a fairly labile epithelium that has a constant cycle of renewal [7]. In the large intestine, the epithelial cycle is basically the same as that in the small intestine. In cases of parasitism, villous atrophy with crypt hypertrophy occurs, a fact observed in the present case. Possibly crypt hypertrophy occurs prior to villous atrophy and occurs independently of previous lesions of the absorptive compartment. This results in the poor absorption of nutrients and water, and increased secretion of water and electrolytes by undifferentiated enterocytes [15].

The degree of dehydration is often estimated during routine clinical examinations and these signs remain evident in dead animals subjected to autopsy. Drying of the dermal connective tissue makes the skin less elastic, as well as deepening or retraction of the eyeball owing to fluid loss from the periorbital and ocular regions (enophthalmia), indicating moderate to severe dehydration [6], facts observed during the necropsy, along with dryness of the tracheal and bronchial mucosae.

Advanced loss of gastrointestinal tract fluids can usually be extensive and lead to progressive dehydration with the loss of isotonic and hypertonic fluids, which can also be observed in the analysis of blood components and severely accelerating changes such as hypovolemia and posterior hemoconcentration [5]. Hemoconcentration makes the blood more viscous and difficult to pump, slowing the blood flow and increasing erythrocyte sedimentation. This fact, after the death of the animal, culminates with the observation of whitish clots (lardaceous clots) in cardiac chambers, as in the present case, and large vessels [15].
In the reported animal, owing to the occurrence of sudden death, there was no possibility of laboratory blood tests to prove severe anemia and hypoproteinemia. Observation of pale mucosa as well as lardaceous clots in the cardiac chambers indicates severe anemia [18].

Intravascular volume depletion associated with hemoconcentration increases blood viscosity, which in addition to reducing organ perfusion, also favors thrombus formation, making hypoperfusion even more severe. These mechanisms decrease cellular oxygenation and increase ischemic tissue damage [3].

Hypovolemia also leads to decreased blood pumping capacity, which may lead to heart failure and pulmonary circulatory disorders with notable effects on gas exchange, which may cause hypoxemia and possibly lethal metabolic acidosis. As these factors lead to a decrease in vessel oncotic/osmotic pressure ratio, diffuse pulmonary congestion is explained by the similarity of a right congestive heart failure [13].

Lack of oxygen may be the cause of findings of hydropic degeneration in the hepatocytes, as it derives from changes in the sodium-potassium pump caused by decreased availability of adenosine triphosphate. This change directly results in the retention of sodium and water in the cell. The cell then acquires an edematous appearance due to imbalances in the osmotic gradient control of the cytoplasmic membrane and the mechanisms of absorption, elimination of water, and intracellular electrolytes [14].

Hypovolemia from severe dehydration also decreases renal perfusion and reduces the rate of glomerular filtration, generating the accumulation of unnecessary and toxic substances in the blood that should be eliminated in the urine. Such changes may result in ischemia, leading to degeneration and necrosis of tubular epithelial cells. These complications can in turn 
culminate in the death of the animal or cause ischemic nephrosis [15], which was observed in this study.

Trichuris vulpis secretes enzymes that possess cytolytic and hemolytic activity, besides having the presence of an oral stylet, which is one of the causes of mechanical damage to the intestinal mucosa. Another mechanical factor is the permanent fencing movement of the anterior part of the parasite associated with a similar movement of its buccal stylus, which enables it to pierce, cut, or tear the tissues and blood vessels [10].

According to Ocarino et al. [15], inflammatory bowel alterations resulting from mucosal injuries cause very large epithelial desquamation, causing the intestinal content to become viscous and darkened, and in severe cases, leading to necrosis. Necrotizing processes are routinely linked to inflammatory processes [1], thus explaining the occurrence of these lesions in this case.

As the function of the large intestine is to recover water and electrolytes through their mucosa, the observed necrosis led to the atrophy of the present villosities and a poor absorption of these compounds, also resulting in severe dehydration [15].

The necropsy performed on the animal found a severe dehydration that could be sustained mainly owing to signs of hypovolemia, associated with a series of pathophysiological events with the massive presence of parasites identified as T. vulpis. The damage caused to the intestinal mucosa by the oral stylet, the movement, and toxins of the parasites led to a severe condition of villosities destruction and tissue necrosis, leading to a large loss in the absorption function of nutrients in the intestines and especially of water, resulting in a condition of severe dehydration.

Dehydration generally leads to hypovolemia, producing hemoconcentration and leading to a decrease in tissue perfusion. These facts are based on the findings of marked enophthalmos and dryness of the viscera and skin. The decrease in blood flow culminates in a decrease in tissue oxygenation, which generates metabolic acidosis with a reduction in blood and tissue $\mathrm{pH}$. Metabolic acidosis is directly related to inadequate excretion and resorption of ions, also influenced by poor renal perfusion related to the observed nephrosis. Poor oxygenation was also a cause of the observed atelectasis and congestion of the pulmonary capillaries.

This imbalance in system functioning also alters cardiac function owing to increased blood viscosity generating possible lardaceous clots, which in turn are indicative of anemia. This cycle of deleterious changes can result in hypovolemic shock and consequent sudden death.

\section{MANUFACTURERS}

${ }^{1}$ Wcor Corantes. São Paulo, SP, Brazil.

${ }^{2}$ Vetec Química Fina Ltda. Rio de Janeiro, RJ, Brazil.

${ }^{3}$ Nikkon Instruments Inc. Melville, NY, USA.

Declaration of interest. The authors report no conflicts of interest. The authors alone are responsible for the content and writing of paper.

\section{REFERENCES}

1 Ackerman M.R. 2018. Inflamação e Cicatrização. In: Zachary J.F. (Ed). Bases da Patologia em Veterinária. 6.ed. Rio de Janeiro: Elsevier, pp.73-131.

2 Anderson R.C., Chabaub A.G. \& Wilmott S. 2009. Enoplida. In: Anderson R.C., Chabaub A.G. \& Wilmott S. (Eds). Keys to the Nematode Parasites of Vertebrates. Archival Volume. Wallingford: CABI Publishing, pp.18-29.

3 Ardissino G., Daccò V., Testa S., Civitillo C.F., Tel F., Possenti I., Belingheri M., Castorina P., Bolsa-Ghiringhelli N., Tedeschi S., Paglialonga F., Salardi S., Consonni D., Zoia E., Salice P. \& Chidini G. 2015. Hemoconcentration: a major risk factor for neurological involvement in hemolytic uremic syndrome. Pediatric Nephrology. 30(2): 345-352.

4 Barutzki D. \& Schaper R. 2003. Endoparasites in Dogs and Cats in Germany 1999 - 2002. Parasitology Research. 90: S148-S150.

5 Brown A.J. \& Otto C.M. 2008. Fluid Therapy in Vomiting and Diarrhea. Veterinary Clinics of North America: Small Animal Practice. 38(3): 653-675.

6 Feitosa F.L.F. 2014. Exame Físico Geral ou de Rotina. In: Feitosa F.L.F. (Ed). Semiologia Veterinária: A Arte do Diagnóstico. 3.ed. São Paulo: Roca, pp.77-102.

7 Frappier B.L. 2012. Sistema digestivo. In: Eurell J.A. \& Frappier B.L. (Eds). Histologia Veterinária de Dellmann. 6.ed. São Paulo: Manole, pp.170-211.

8 Hendrix C.M., Blagburn B.L. \& Lindsay D.S. 1987. Whipworms and Intestinal Threadworms. Veterinary Clinics of North America: Small Animal Practice. 17(6): 1355-1375. 
9 Hoffmann R.P. 1987. Diagnóstico de Parasitismo Veterinário. Porto Alegre: Sulina, pp. 40-70.

10 Kirkova Z. \& Dinev I. 2005. Morphological changes in the intestine of dogs, experimentally infected with Trichuris vulpis. Bulgarian Journal of Veterinary Medicine. 8(4): 239-243.

11 Martins C.M., Barros C.C., Bier D., Marinho AP., Figueiredo J.M.G., Hoffmann J.L., Molento M.B. \& Biondo A.W. 2012. Dog parasite incidence and risk factors, from sampling after one-year interval, in Pinhais, Brazil. Revista Brasileira de Parasitologia Veterinária. 21(2): 101-106.

12 Medina-Pinto R.A., Rodríguez-Vivas R.I. \& Bolio-González M.E. 2018. Zoonotic intestinal nematodes in dogs from public parks in Yucatán, México. Biomedica. 38(1): 105-110.

13 Miller L.M. \& Gal A. 2018. Sistema Cardiovascular e Vasos Linfáticos. In: Zachary J.F. (Ed). Bases da Patologia em Veterinária. 6.ed. Rio de Janeiro: Elsevier, pp. 561-616.

14 Miranda P.C. \& Santos P.C.G. 2008. Degeneração Hidrópica. Revista Científica Eletrônica de Medicina Veterinária. 10: $4 \mathrm{p}$.

15 Ocarino N.M., Paixão T.A., Carvalho E.C. \& Gimeno E.J. 2016. Sistema Cardiovascular. In: Santos R.L. \& Alessi A.C. (Eds). Patologia Veterinária. 2.ed. Rio de Janeiro: Roca, pp.51-88.

16 Ramos D.G.S., Zocco B.K.A., Torres M.M., Braga Í.A., Pacheco R.C. \& Sinkoc A.L. 2015. Helminths parasites of stray dogs (Canis lupus familiaris) from Cuiabá, Midwestern of Brazil. Semina: Ciências Agrárias. 36(2): 889-893.

17 Ribeiro C.M., Lima D.E. \& Katagiri S. 2015. Infecções por parasitos gastrintestinais em cães domiciliados e suas implicações na transmissão zoonótica. Veterinária e Zootecnia. 22(2): 238-244.

18 Van Vleet J.F. \& Ferrans V.J. 2009. Sistema cardiovascular. In: Mcgavin M.D. \& Zachary J.F. (Eds). Bases da Patologia em Veterinária. 4.ed. Rio de Janeiro: Elsevier, pp.559-614.

19 Vieira V.S.F., Pires M.S., Saavedra A.F., Figueiredo K.G., Scott F.B. \& Rodrigues M.L.A. 2016. Experimental infection of Trichuris vulpis in dogs. Brazilian Journal of Veterinary Medicine. 38: 136-138.

20 Yevstafieva V.A., Kravchenko S.O., Gutyj B.V., Melnychuk V.V., Kovalenko P.N. \& Volovyk L.B. 2019. Morphobiological analysis of Trichuris vulpis (Nematoda, Trichuridae), obtained from domestic dogs. Regulatory Mechanisms in Biosystems. 10(2): 165-171. 